\title{
International Perspectives on General Internal Medicine and the Case for "Globalization" of a Discipline
}

\author{
William A. Ghali, MD, MPH, ${ }^{7}$ Peter B. Greenberg, MD, PhD, ${ }^{2}$ Raul Mejia, MD, ${ }^{3}$ \\ Junji Otaki, MD, DMedSc, ${ }^{4}$ Jacques Cornuz, MD, $\mathrm{MPH}^{5}$ \\ 'Departments of Medicine and Community Health Sciences, and the Centre for Health and Policy Studies, University of Calgary, Calgary, \\ AB, Canada; ${ }^{2}$ Department of Medicine, University of Melbourne, Melbourne, Australia; ${ }^{3}$ General Internal Medicine Program, Hospital de \\ Clinicas, Buenos Aires University, Buenos Aires, Argentina; ${ }^{4}$ International Research Center for Medical Education, University of Tokyo, \\ Tokyo, Japan; ${ }^{5}$ Department of Medicine and Institute of Social and Preventive Medicine, University of Lausanne, Lausanne, Switzerland.
}

General internal medicine (GIM) has flourished in the United States (U.S.). Unlike other subspecialties of internal medicine, however, GIM's evolution has not been global in scope, but rather appears to have occurred in isolation within countries. Here, we describe international models of GIM from Canada, Switzerland, Australia/New Zealand, Argentina, and Japan, and compare these with the U.S. model. There are notable differences in the typical clinical roles assumed by General Internists across these 7 countries, but also important overlap in clinical and academic domains. Despite this overlap, there has been a relative lack of contact among General Internists from these and other countries at a truly international GIM meeting; the time is now for increased international exchange and the "globalization" of GIM.

KEY WORDS: general internal medicine; primary care; hospitalists; human resources; academic medicine.

DOI: $10.1111 /$ j. 1525-1497.2005.00289x.

J GEN INTERN MED 2006; 21:197-200.

$\mathrm{G}$ eneral internal medicine (GIM) has flourished in the United States (U.S.) in recent years ${ }^{1}$ with the widespread development of academic divisions of GIM in almost all U.S. medical schools. ${ }^{2-4}$ The growth of GIM is remarkable considering how young it is as an academic discipline, with the trend toward the development of divisions of GIM in the U.S. beginning only in the early 1970 s as a result of a recognized need for increased numbers of physicians capable of providing comprehensive care to adults in ambulatory settings. This was followed by the formation of the Society of General Internal Medicine (SGIM) in $1977,{ }^{5}$ and by the establishment of the Journal of General Internal Medicine in 1986. These vehicles have helped U.S. General Internists to define themselves clinically and academically as clinician educators, clinician researchers, primary care physicians, and hospitalists (the latter of whom spend at least $25 \%$ of their time caring for hospitalized patients in a clinical profile that contrasts with that of many other American General Internists who spend a majority of their time in out patient primary care settings).

The evolution of GIM in the U.S. has occurred in parallel to the discipline's evolution in other countries, where GIM appears to have taken a somewhat different course. Here, we briefly describe the profiles of GIM in Canada, Switzerland,

The authors have no conflicts of interest to report.

Address correspondence and requests for reprints to Dr. Ghali: Faculty of Medicine, University of Calgary, 3330 Hospital Drive N.W., Calgary, AB, Canada T2N 4N1 (e-mail: wghali@ucalgary.ca).
Australia/New Zealand, Argentina, and Japan, all developed countries that have an identifiable specialty of GIM. These particular countries are described because 4 of them (Canada, Switzerland, Argentina, and Japan) are the only countries other than the U.S. that have a notable membership (i.e., more than 1 or 2 members) in the U.S.-based SGIM (David Karlson, personal communication March 23, 2004). The GIM model from Australia and New Zealand is also presented because it has been described in the peer-reviewed literature. ${ }^{6-8}$

The merit of discussing international models of GIM relates to the discipline's growth, both inside and outside the U.S. that will, we except, result in an eventual "globalization" of the discipline. The discipline has until now grown and evolved within countries, with relatively little "cross-pollination" across international borders. This is in contrast to disciplines like cardiology and gastroenterology that represent firmly established international entities, and for which large annual international meetings are staged. The U.S.-based SGIM certainly has some international members and attendees to its annual meetings, but many of these individuals developed their ties to SGIM through a period of academic GIM training in the U.S. or because they have been encouraged to attend SGIM meetings by colleagues who themselves gained first-hand exposure to SGIM while training in the U.S.

The potential benefits of globalizing GIM as a discipline are many, and a key first step toward such globalization is an improved collective understanding of both the clinical and academic elements of existing GIM models. The U.S. model has been comprehensively described by Levinson and Linzer. ${ }^{1} \mathrm{Be}-$ low, we provide brief descriptions of GIM models from several other countries, with more detailed descriptions of each country available online (see References).

\section{GIM in Canada}

The clinical profile of GIM in Canada ${ }^{9-13}$ differs somewhat from that in the U.S., with the most notable difference being that Canadian General Internists rarely assume a primary care role. It has in fact been explicitly proposed that Canadian General Internists should avoid the primary care role ${ }^{10}$ to instead focus on providing consultative support to primary care general practitioners. Recognizing that subspecialties like cardi-

Manuscript received November 29, 2005

Initial editorial decision December 7, 2005

Final acceptance September 2, 2005 
ology and gastroenterology also exist, General Internists in Canada have assumed a "secondary-level" consultant role in which they provide consultative support to general practitioners for certain problems, but also occasionally require further consultative support from subspecialists, particularly when high-technology procedural care is required. Because of their coexistence with subspecialty consultants, Canadian General Internists have tended to be consulted for patients with undifferentiated symptom presentations and/or multisystem disease-i.e., cases where single-system subspecialists may be less suitable consultants.

There are also some similarities between General Internists in Canada and the U.S. Most notably, many General Internists in Canada are hospital based and provide care for hospitalized adults in a role that is essentially identical to that of GIM "hospitalists" in the U.S. ${ }^{14,15}$ Many Canadian General Internists also provide outpatient care in parallel to their inpatient activities, while less commonly, some provide only outpatient consultative care without any inpatient role.

Meanwhile, the academic profiles of General Internists in Canada closely resemble those in the U.S., with activity in the areas of medical education, clinical epidemiology (e.g. promoting "evidence-based medicine" ${ }^{9,16}$ ), health services research, bioethics, medical informatics, and clinical pharmacology. These activities clearly identify areas of synergy with counterparts in the U.S.

\section{GIM in Switzerland}

General Internists in Switzerland have historically participated in hospital-based care, but the hospital care setting in Switzerland has seen a large penetration of subspecialists that has led General Internists to shift their focus toward a primary care role similar to that assumed by General Internists in the U.S. This trend is so pronounced that certain Swiss regions have seen their regional societies of GIM merge with corresponding regional societies of family medicine to create single entities representing the shared academic and professional interests of primary care physicians.

Some Swiss General Internists have, however, also assumed a clinical role that distinguishes GIM in Switzerland from all of the countries discussed here-that of staffing the non-surgical portions of emergency rooms. This arises partly from the fact that Switzerland does not have an independent specialty of emergency medicine. Instead, emergency room physicians emerge from Swiss internal medicine training programs that typically incorporate focused periods of training in the emergency room setting.

The academic profile of GIM in Switzerland closely resembles that of GIM in the U.S. and Canada, with academic activity in the areas of clinical epidemiology, health services research, and medical education. The emergence of the discipline is being increasingly recognized within Swiss academic medicine, as evidenced by the awarding of national prizes to General Internists in 2002 and 2003 for outstanding research presented at the annual Swiss Society of Internal Medicine meeting. ${ }^{17}$

\section{GIM in Australia and New Zealand}

The profiles of General Internists in Australia and New Zealand are described in the literature, ${ }^{6-8,18}$ and closely resemble those of Canadian General Internists. Specifically, General Intern- ists in Australia and New Zealand have assumed a predominantly consultative role in which they respond to referrals from general practitioners, while coexisting with subspecialists. There is a formal mechanism through physician reimbursement schemes for General Internists to assume "indefinite care" for certain patients. In such situations, the General Internist assumes a de facto primary care role, although it still arises from their positions as consultants. Most General Internists have public hospital appointments and provide care to hospitalized inpatients in addition to their ambulatory practice activities, with the balance of outpatient versus inpatient activity varying from physician to physician.

The academic activities of General Internists in the region are generally in areas such as clinical epidemiology, health services research, and medical education. ${ }^{6}$ These academic activities are thus in keeping with those of General Internists in the other countries discussed.

\section{GIM in Argentina}

The development of GIM as a discipline in Argentina is relatively recent, as a result of coordinated outreach activities from the U.S.-based SGIM, and a primary care training program at the Mount Sinai School of Medicine. These U.S.-based groups began working with the University of Buenos Aires in 1987 to develop a training program focusing on outpatient primary care. ${ }^{19-22}$ Since then, the field of GIM has gone on to flourish in Argentina, with the formation of a society of GIM in Argentina that succeeds in attracting many into the discipline.

As a result of its history and links to U.S.-based GIM, the discipline's emphasis in Argentina has been on outpatient primary care, with comparatively little involvement in the inpatient care setting. That said, there is a single training program, established in 1995, that has recently introduced training for GIM "hospitalists."

The academic activities of General Internists in Argentina again overlap with those of General Internists in the other countries discussed. The outpatient emphasis of the discipline in Argentina steers the content areas of academic work toward primary care themes.

\section{GIM in Japan}

GIM is perhaps less well established in Japan than in the other countries discussed here, because until very recently, there has been a general lack of standardized training programs and societies to train and subsequently represent primary care physicians. As a result, primary care has historically been provided by hospital-based physicians from a variety of training backgrounds who move their practices to the outpatient setting in mid-to-late career. ${ }^{23,24}$ It is only in the late 1980 s and early 1990s that formal training programs for outpatient primary care have developed, along with corresponding professional societies-the Japanese Academy of Family Medicine (1986) and the Japanese Society of General Medicine (1994). ${ }^{25-27}$ A recognizable discipline of GIM has emerged from these entitites, and the typical profile predominantly involves outpatient primary care, although the short history of the discipline and heterogeneous nature of training paths taken by Japanese General Internists dictate that some are also involved in various forms of inpatient care, and even occasionally front-line emergency room care. 
Academically, Japanese Divisions of GIM exist in various medical schools, and their members are engaging in the same types of academic activities that define GIM in other countries. The existing Divisions are generally small (e.g., 3-4 faculty members per site), but are gradually increasing the discipline's profile.

\section{DISCUSSION}

The relevance of these descriptions of GIM models from outside of the U.S. lies in the notable similarities across countries. Indeed, it is clear that while there are some differences in the clinical roles assumed by General Internists in the countries being discussed here, there are also more importantly many similarities (see synthesis in Table 1). Furthermore, the magnitude of differences across countries lessens when one considers that a variety of typical GIM profiles already exist within countries, as evidenced, for example, by the evolution of the hospitalist profile as a recognized subdiscipline of GIM in the U.S. Borrowing metaphorically from the field of biostatistics, it seems that the existing "within-country variance" in GIM profiles is not all that different from the "between-country variance."

The synergies among the GIM profiles discussed above are clear, particularly in relation to academic activities in areas such as clinical epidemiology, health services research, and medical education. Beyond academic endeavors, there is also considerable overlap of clinical roles across countries, although the areas of clinical overlap do not necessarily apply to all countries. General Internists in Canada and Australia/ New Zealand have obvious similarities in their roles that distinguish them from General Internists in the U.S., Argentina, and Japan, given the predominantly consultative roles of the former relative to the primary care roles of the latter. And indeed, it is the recognition of such differences that has historically limited international cross-pollination in GIM. Yet, despite these seemingly different clinical profiles, there are nonetheless many shared clinical issues that are relevant to General Internists in all of these countries. These include, for example, updates in the outpatient management of diabetes, hypertension management, secondary prevention of cardiovascular risk, optimal approaches to behavioral counseling, the shared challenges of staffing rural and underserviced areas, and how to incorporate new diagnostic and therapeutic technologies into usual care.

Some international linkages between General Internists in various countries have certainly developed, although it seems that the majority of such linkages have been somewhat haphazard (with perhaps the exception of the U.S.-Argentina collaboration described earlier). Some countries have a long history of GIM existing as a professional entity, albeit in evolution, while others like Argentina and Japan have relatively young disciplines of GIM that stand to benefit tremendously from the "lessons of history" in other countries-lessons that can only be fully shared through formalized international interaction and communication.

A recently published Charter on Medical Professionalism $^{28}$ articulates the need for "commitment to professional competence and scientific knowledge" among physicians; enhanced international cross-pollination and knowledge exchange would contribute importantly to the fulfillment of this commitment. Through unprecedented staging of a recent SGIM Annual Meeting in Canada (Vancouver in May 2003), and the inclusion in the meeting's program of high-profile sessions featuring Canada's health care system, the leadership of SGIM has demonstrated a clear interest in exposing its membership to international system models and the roles of Internists within these models. We applaud those early steps and expect that the next steps will be to enhance the society's international outreach.

As already mentioned, we anticipate that the current level of international involvement in SGIM has arisen largely through the ad-hoc exposure of non-U.S. Internists to the Society during periods of training in the U.S.. For each of the 4 non-U.S. countries notably represented in SGIM membership (Canada, Switzerland, Argentina, and Japan), the representation typically arises from traceable links through individuals who spent time in U.S.-based academic training, rather than from any international outreach activities from the Society. The relative lack of representation of involvement in SGIM of General Internists from Australia, New Zealand, the United Kingdom, and other European countries is notable, and underlines the considerable potential for increased international outreach of SGIM.

Some may argue that SGIM has benefited from its relatively small size and its focus on American health policy issues, and that increased international outreach could detract from the society's mission and current strength. It could also be argued that there will always be a need for a U.S.-based society that focuses primarily on American health system issues. And perhaps it is not SGIM itself that should reach out to become a larger international society, but rather a new international entity. Such positions have merit, but it is clear that the U.S.-based SGIM is already developing an increasingly international perspective (e.g., through the staging of its annual meeting in Canada), and that the remarkable academic strength and vibrancy of the Society make it the de facto choice for leadership of a move toward the "globalization" of the discipline. Such globalization can continue to progress slowly

Table 1. Summary of Clinical Roles* Assumed by General Internists in Several Countries

\begin{tabular}{|c|c|c|c|c|c|c|}
\hline Role & U.S. & Canada & Switzerland & Australia/NZ & Argentina & Japan \\
\hline Outpatient primary care role & +++ & - & ++ & - & +++ & +++ \\
\hline Consultative role & ++ & +++ & ++ & +++ & ++ & + \\
\hline In-hospital care role & +++ & +++ & +++ & +++ & + & ++ \\
\hline First-line emergency room care role & - & - & +++ & - & - & + \\
\hline
\end{tabular}

${ }^{*}$ Ratings: +++ , major role; ++ , moderate role;,+ minor role and,- little or no role and are based on our narrative review of published papers on roles of General Internists in the 7 countries discussed here.

NZ, New Zealand. 
through the current mechanisms of word-of-mouth and ad hoc links. Or alternatively, SGIM could proactively adopt a coordinated and targeted international outreach strategy to build bridges with societies of internal medicine in other countries. We endorse the latter approach, recognizing that this would represent an important strategic policy shift for SGIM. The resulting international society will, of course, face the challenge of assuming a global perspective on health care delivery issues, and the shared research and education agendas that would define a global society of GIM.

In closing, we present a vision for a large international GIM meeting in 2010, attended by perhaps as many as 1000 international (non-U.S. based) attendees from across the world. Such a gathering will permit a broadly international perspective, with dialogue around contemporary issues in clinical and academic GIM, exchange of ideas around health system models, and the spawning of new multinational collaborative ties in education and research. We cannot wait!

Dr. Ghali is supported by a Health Scholar Award from the Alberta Heritage Foundation for Medical Research, and by a Government of Canada Research Chair in Health Services Research. He thanks the Department of Medicine and Institute for Social and Preventive Medicine, University of Lausanne, for hosting him during a sabbatical period.

\section{REFERENCES}

1. Levinson W, Linzer M. What is an academic general internist? Career options and training pathways. JAMA. 2002;288:2045-8.

2. Friedman RH, Pozen JT. The academic viability of general internal medicine. Ann Intern Med. 1985; 103:439-44.

3. Friedman RH. Growing up: the status of academic internal medicine. J Gen Intern Med. 1986;1:134-6.

4. Friedman RH, Pozen JT, Rosencrans AB, et al. General internal medicine units in academic medical centers. Ann Intern Med. 1982;96:2338 .

5. http://www.sgim.org/ (accessed December 3, 2003).

6. Scott IA, Greenberg PB. General internal medicine in Australia and New Zealand-a renaissance. Med J Aust. 1998;168:104-5.

7. Cohen A, Greenberg PB, Graham I. General internal medicine in Australasia. Int Med J. 2002;32:495-7.

8. Greenberg PB. A place for general medicine among the subspecialties. Med J Aust. 1994;160:100-2.
9. Cook DJ, Sackett DL. Roles of the Canadian general internist. Ann R Coll Physicians Surg Can. 1995;28:172-4.

10. Spaulding WB. The role of the general internist. Ann R Coll Physicians Surg Can. 1973;6:99-103.

11. Hollenberg $\mathbf{C H}$. The re-emergence of the general internist in the teaching hospital. CMAJ. 1982;127:809-10.

12. Hollenberg CH, Langley GR. The Canadian general internist: education and future role. CMAJ. 1978;118:397-400.

13. Ho Ping Kong H, Flegel KM, Coke W, Hoey HR. General internal medicine reappears in the teaching hospitals: the experience of Royal Victoria Hospital. CMAJ. 1982;127:837-40.

14. Wachter R, Flanders S. The hospitalist movement and the future of academic general internal medicine. J Gen Intern Med. 1998;13:783-5.

15. Wachter RM, Goldman L. The hospitalist movement 5 years later. JAMA. 2002;287:487-94.

16. Evidence-Based Medicine Working Group. Evidence-based medicine: a new approach to the teaching and practice of medicine. JAMA. 1992; 268:2420-5.

17. http://www.unil.ch/fbm/ (accessed October 2004).

18. Scott IA, Greenberg PB. General internal medicine. Med J Aust. 2002;176:16.

19. Bosch SJ, Merino R, Fischer E, Deuschle KW. The international role of a U.S. medical school in the development of health services. Am J Prev Med. 1985;1:44-7.

20. Bosch SJ. El proyecto consorcio panamericano para el Desarrollo de políticas de Salud: un programa de Cooperación Técnica entre Países de América. Revista Federación Panamericana Facultades Med. 1988; 24:10-6.

21. Bosch SJ, Silver AL. Teaching and learning community medicine with foreign physicians who return to their home countries. The graduate education of foreign physicians in public health and preventive medicine. In: Wadell Steele W., Oesterling SF, eds. The Roles of United States Teaching Institutions. Washington: ECFMG; 1984:19.

22. Vazquez E, Casal E, Perez Stable EJ, Silver A, Bosch S. El Desarrollo de la medicina interna general en Argentina. Medicina y Sociedad. 1993;16:31-9.

23. Yano E, Yamaoka K, Sugita S, et al. Comparing postgraduate medical education at university and non-university hospitals in Japan. Acad Med. 1992;67:54-8.

24. Ikegami N, Campbell JC. Medical care in Japan. N Engl J Med. 1995;333:1295-9.

25. Smith BWH, Demers R, Garcia-Shelton L. Family medicine in Japan. Arch Fam Med. 1997;6:59-62.

26. Otaki J. Considering primary care in Japan. Acad Med. 1998;73:662-8.

27. Bito S, Fukuhara S, Shapiro MF, et al. Relationship between having a home doctor and outpatient utilization. J Epidemiol. 2001;11: 160-9.

28. Medical Professionalism Group. Medical professionalism in the new millennium: a physicians' charter. Ann Intern Med. 2002;136:243-6.

\section{Supplementary Material}

The following supplementary material is available for this article online www.blackwell-synergy.com

GIM in Canada, Switzerland, Australia, New Zealand, Argentina, and Japan. 